\title{
Panic and Depressive Disorders Among Psychiatrically Hospitalized Adolescents
}

\author{
Norman E. Alessi, Douglas R. Robbins, and Steven C. Dilsaver \\ Received January 21, 1986; revised version received December 10, 1986; accepted December \\ $19,1986$.
}

\begin{abstract}
Sixty-one adolescents hospitalized on an inpatient psychiatric unit were evaluated to determine whether they met criteria for panic and affective disorders according to Research Diagnostic Criteria. Ten $(16 \%)$ and $15(24 \%)$ met criteria for definite or possible panic disorder. Fifteen $(24.5 \%)$ had major depressive disorder (MDD) endogenous subtype, $10(16 \%)$ had MDD nonendogenous subtype, $8(13 \%)$ had minor depressive disorder (mDD), and $27(44 \%)$ had no diagnosable mood disorder. Four adolescents with definite panic disorders were diagnosed as having MDD endogenous subtype, three MDD, two mDD, and one had no diagnosable depressive disorder. The mean total score on the Hamilton Rating Scalc for Depression (HRSD) was significantly higher among those subjects with definite panic attacks compared with those with either possible or no panic. Patients with definite panic disorder showed significant increases on the HRSD items of guilt, decreased work and interest, psychological and somatic anxiety, and weight loss compared to these samples.
\end{abstract}

Key Words. Adolescence, affective disorders, depression, panic disorder.

Descriptive, psychobiological, and pharmacological studies have suggested a relationship between affective disorder and panic disorder (Klein, 1964; Bowen and Kohout, 1979; Munjack and Moss, 1981; Roth et al., 1982; Leckman et al., 1983; Breier et al., 1984). Despite the evidence strongly indicating an association between panic attacks or panic disorder and depressive illness in adults, there is ittle information about the relationship of these phenomena in adolescents. The occurrence of panic disorder or attacks has not been documented in this age group. In a study by Strober et al. (1981 b) determining the occurrence of several psychiatric disorders among adolescents $(n=95)$, two $(2.1 \%)$ met criteria for some form of anxiety disorder, but none was identified as having panic attacks. Similarly, Hershberg et al. (1982) and Kovacs et al. (1984) reported the coexistence of anxiety and depressive disorders in children and adolescents, but did not identify subjects meeting criteria for panic disorder or attacks. Breier et al. (1984), however, reported that five adults with panic disorder gave a history suggesting that their first panic

\footnotetext{
Norman E. Alessi, M.D., and Steven C. Dilsaver, M.D., are Assistant Professors, Department of Psychiatry, University of Michigan. Douglas R. Robbins, M.D., is Assistant Professor of Psychiatry, Brown University Program in Medicine, Bradly Hospital. (Reprint requests to Dr. N.E. Alessi, Mental Health Research Institute, 205 Washtenaw Pl., Ann Arbor, MI 48109, USA.)
} 
attack occurred either during latency (age 10) or in late adolescence (mean age $=17.5$ years). The investigators concluded that two of these subjects had concurrent major depressive episodes at the time of their first panic attack.

The present study reports data on 61 psychiatrically hospitalized adolescents who were evaluated to determine the presence of panic attacks and/or disorder and depressive illness.

\section{Methods}

Patients admitted to the adoleseent unit, University of Michigan, were intervicwed by two board-certified child psychiatrists using the Schedule for Affective Disorders and Schizophrenia (SADS) (Spitzer and Endicott, 1978), and diagnosed using Research Diagnostic Criteria (RDC) (Spitzer et al., 1977) within 3 weeks of admission. Our group (Robbins et al., 1982: Alessi et al., 1984; Alessi and Robbins, 1984) and others (Strober et al., 1981 a, 1981b) have established that major depressive disorder (MDD) can be reliably diagnosed during adolescence. The Hamilton Rating Scale for Depression (HRSD) was completed by the SADS interviewer (Hamilton, 1960; Robbins et al., 1985). The SADS includes a structured evaluation for a history of panic attacks that permits one to determine whether subjects meet criteria for panic disorder.

The R DC and SADS determine the vecun sence of "panic disondes" according to the degree of certainty the obtained data allow. The three categories used are "none" (the subject does not have panic attacks), "questionable" or "possible," and "definite" panic disorder. A patient could have a possible panic disorder either because the attacks had only 1 of 10 possible physical symptoms (dyspnea, palpitations, chest pain or discomfort, smothering or choking feeling, dizziness, paresthesias, faintness, diaphoresis, trembling or shaking, and fear of dying or losing control) or because of uncertainty that the periods represented intense anxiety without discrete onset. Definite panic attacks involve intense anxiety with a discrete onset of at least two of the symptoms noted above.

Separation-anxiety disorders, conduct disorders, and personality disorders were diagnosed independently of the SADS interview according to DSM-III criteria (American Psychiatric Association, 1980).

Statistical Analysis. Statistical procedures included analysis of variance ( $N$ NOVA) for continuous data, $X^{2}$ for analysis of dichotomous variables, $Z$ proportions, and Cohen's kappa. Analyses were carried out using MIDAS on the Michigan Terminal Systein.

\section{Results}

The sample comprised 61 consecutively admitted patients to the adolescent unit. The interrater reliability for the diagnosis of panic attacks using the information obtained in the SADS interview was 0.66 (Cohen's kappa; Bishop et al., 1975). Table 1 gives the distribution within the sample for the presence (definit a or possible) or absence (none) of panic attacks. These groups did not differ by age (ANOVA, NS) or sex $\left(X^{2}\right.$, NS). The Fisher's exact probability test disclosed a trend for more females than males to have panic attacks. The mean HRSD score of the sample with definite panic disorder was higher than that of those with either possible or no panic disorder (ANOVA, $d f=2, p<0.03$ ).

Depressive disorders occurred in $56 \%$ of the 61 patients. These patients included 15 subjects with MDD endogenous subtype, 10 with MDD, and 8 with minor depressive disorder (mDD). Twenty-seven had no diagnosable depressive disorder. 
Table 1. Psychiatrically hospitalized adolescents with panic attacks and concurrent depressive disorders

\begin{tabular}{|c|c|c|c|c|c|c|c|}
\hline \multicolumn{3}{|c|}{ Panic disorders } & \multicolumn{5}{|c|}{ Depressive disorders } \\
\hline Occurrence & $\begin{array}{c}\text { Age' } \\
\text { (years) } \\
\text { (mean } \\
\pm \mathrm{SD} \text { ) }\end{array}$ & $\begin{array}{l}\operatorname{Sex}^{2} \\
(M: F)\end{array}$ & $\begin{array}{l}\text { HRSD }^{3} \\
\text { (mean } \\
\pm \mathrm{SD} \text { ) }\end{array}$ & $\begin{array}{c}\text { MDDe } \\
(n=15)\end{array}$ & $\begin{array}{c}\text { MDDn } \\
(n=11)\end{array}$ & $\begin{array}{c}\text { mDD } \\
(n=8)\end{array}$ & $\begin{array}{c}\text { None }^{2} \\
(n=27)\end{array}$ \\
\hline $\begin{array}{l}\text { Definite } \\
\qquad(n=10)\end{array}$ & $15.8 \pm 0.8$ & 4: 6 & $18.7 \pm 10.5$ & 4 & 3 & 2 & 1 \\
\hline $\begin{array}{l}\text { Probable } \\
\qquad(n=15)\end{array}$ & $15.2 \pm 1.7$ & $3: 12$ & $12.1 \pm 6.8$ & 3 & 3 & - & 9 \\
\hline $\begin{array}{l}\text { None } \\
\qquad(n=36)\end{array}$ & $15.1 \pm 1.4$ & $18: 18$ & $11.8 \pm 6.6$ & 8 & 5 & 6 & 17 \\
\hline
\end{tabular}

Abbreviations: HRSD = Hamilton Rating Scale for Depression. MDDe = major depressive disorder, endogenous. $\mathrm{MDDn}=$ major depressive disorder, nonendogenous; $\mathrm{mDD}=$ minor depressive disorder.

1. Analysis of variance, NS.

2. $x^{2}$, NS. If definite/questionable cases were collapsed, then trend found more females with panic attacks (Fisher exact probability, 0.07)

3. HRSD total score, analysis of variance, $F=3.6119, d f=2, p<0.03$.

The mean $( \pm \mathrm{SD})$ ages of these groups were $15.7 \pm 5.4,15.3 \pm 3.0,14.9 \pm 3.7$, and $15.0 \pm 7.8$ years, respectively. The male to female ratios for the four groups were $7: 8$, $4: 7,2: 6$, and $12: 15$, respectively. The mean ( \pm SD) HRSD total scores for the groups were $19.9 \pm 7.8,14.2 \pm 8.6,8.6 \pm 4.1$, and $9.9 \pm 6.2$, respectively.

Table 2 lists those patients with definite panic attacks and associated depressive disorders and pertinent variables. The mean $( \pm S D)$ age at the onset of panic attacks was $13.87 \pm 1.58$ for this group as compared to $14.0 \pm 3.95$ for the onset of the first depressive episode. Further, the number of consecutive weeks in which these patients had panic attacks varied from 4 to 9 with a mean $( \pm S D)$ of $8.11 \pm 5.79$. Due to the retrospective design of this study and the tendency for subjects not to experience depressive episodes as being discrete events, the number of episodes could not be determined. Four of the adolescents had separation-anxiety disorders as children. Three were previously diagnosed as having conduct disorders, socialized nonaggressive type; two as having obsessive-compulsive personality disorder; and two others. borderline personality disorder (BPD). Three had no previously diagnosed psychiatric illness. Three of the 10 panic disorder patients had a history of substance abuse (cases 4,6 , and 8). Two were polysubstance abusers, and one abused marijuana alone.

Table 3 displays the frequency of panic symptoms in subjects with panic disorders. Sweating, trembling, palpitations, and feelings of faintness occurred in more than $50 \%$ of them. Table 4 lists the mean ( \pm SD) score of individual items on the HRSD for subjects with panic attacks. Scores on the HRSD subscales of guilt $(p<0.007)$, decreased work and interest $(p<0.05)$, psychic anxiety $(p<0.004)$, somatic anxiety $(p<0.007)$, and weight loss $(p<0.02)$ differed significantly (ANOVA). Patients with MDD endogenous subtype had higher scores on the depressed mood, guilt, suicide, initial and delayed insomnia, work and interest, retardation, gastrointestinal symptoms, and loss of insight subscales compared to other depressed groups and nonde- 


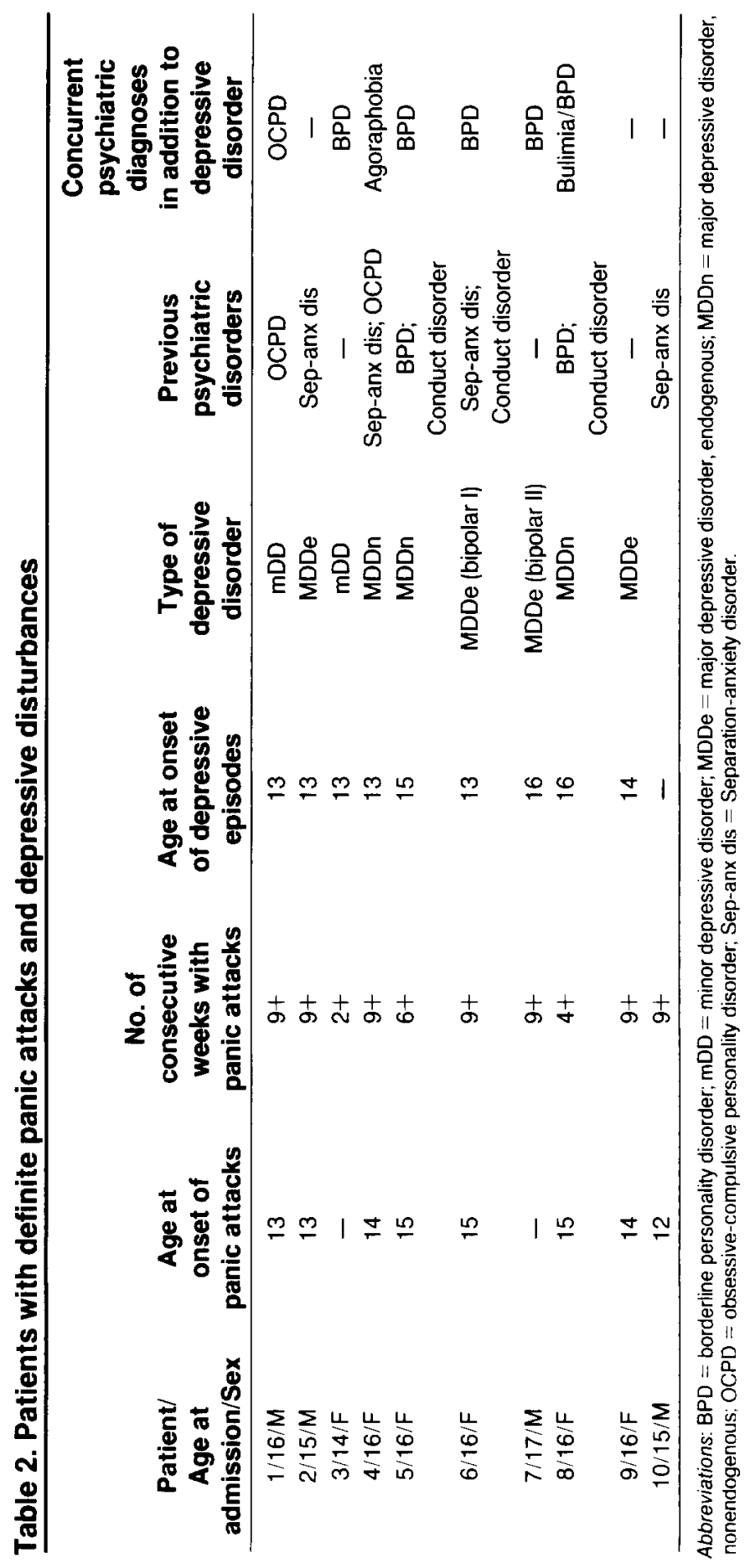




\section{Table 3. Panic symptoms among adolescents with definite panic disorder}

\begin{tabular}{lcc}
\hline & \multicolumn{2}{c}{ Definite $(\boldsymbol{n}=\mathbf{1 0})$} \\
\cline { 2 - 3 } Symptom & No. & $\%$ \\
\hline Trembling & $9^{1}$ & $90 \%$ \\
Sweaty & $7^{2}$ & $70 \%$ \\
Palpitations & 6 & $60 \%$ \\
Faint & 5 & $50 \%$ \\
Choking & 4 & $40 \%$ \\
Dizzy & 4 & $40 \%$ \\
Tingling & 4 & $40 \%$ \\
Chest pain & 2 & $20 \%$ \\
Fear of death & 1 & $10 \%$ \\
\hline
\end{tabular}

1. Trembling $(9 / 10)$ occurs significantly more frequently than any symptom which occurs $4 / 10$ or fewer $(Z$ for proportions, $p<0.05$ ).

2 . Sweating $(7 / 10)$ occurs significantly more frequently than chest pains $(2 / 10)$ or fear of dying $(1 / 10)(Z$ for proportions, $p<0.05)$.

pressed subjects. Scores on the psychic and somatic anxiety subscales did not differentiate subgroups of depressed subjects. Further, the distribution of definite or possible panic disorders did not differ among the affective disorder subgroups.

\section{Discussion}

This study strongly suggests that panic attacks can be reliably diagnosed in adolescent patients. Among 61 consecutively admitted patients to an inpatient adolescent unit, $10(15 \%)$ of the patients fulfilled RDC for definite panic disorders. Similar to findings in adult samples, panic attacks were frequently accompanied by a depressive disorder ( 7 of 10 cases). Separation-anxiety disorders had been previously identified in 4 of the 10 cases. Autonomic characteristics of panic attacks - trembling, sweating, palpitations, and faintness-each occurred in $50-90 \%$ of the cases. Several HRSD subscales, including psychic and somatic anxiety, guilt feelings, work and interest, and weight loss, distinguish the sample with definite panic disorders. However, the HRSD subscales of psychic and somatic anxiety did not differentiate the depressive subgroups.

This is the first study reporting on panic disorder in adolescents. The SADSderived data lead to the diagnosis of definite and possible panic disorders in $10(15 \%)$ and $15(24 \%)$ of the cases, respectively. Although previous studies of depression and anxiety among children and adolescents (7-17 years of age) have noted the presence of symptoms characteristic of several anxiety disorders, none have recognized the presence of discrete panic disorder. In younger subjects, panic-like symptoms appear to be related to either school phobia or separation-anxiety disorders. Despite an extensive literature among adults highlighting the relationship between panic attacks and affective disorders, this is the first report of the concurrence of panic attacks and depressive illness among adolescents (Gurney et al., 1972; Schapinz et al., 1972; Dealy et al., 1981; Roth et al., 1982; Fawcett and Kravitz, 1983). Hershberg et al. (1982) and Kovacs et al. (1984) reported an association of anxiety symptoms and 
Table 4. Items from the Hamilton Rating Scale for Depression (mean \pm SD)

\begin{tabular}{|c|c|c|c|c|}
\hline Hamilton items & $\begin{array}{c}\text { Panic disorder } \\
\text { definite } \\
(n=10) \\
\end{array}$ & $\begin{array}{c}\text { Panic disorder } \\
\text { probable } \\
(n=15) \\
\end{array}$ & $\begin{array}{l}\text { No panic } \\
\text { disorder } \\
(n=36)\end{array}$ & ANOVA \\
\hline Depressed mood & $2.22 \pm 1.20$ & $1.20 \pm 1.08$ & $1.67 \pm 1.20$ & NS \\
\hline Guill feelings & $1.89 \pm 1.05$ & $0.60 \pm 0.74$ & $1.00 \pm 0.99$ & $p<0.007^{1}$ \\
\hline Suicide & $1.00 \pm 1.32$ & $1.00 \pm 1.52$ & $1.14 \pm 1.31$ & NS \\
\hline Initial insomnia & $0.89 \pm 0.93$ & $0.73 \pm 0.96$ & $0.67 \pm 0.89$ & NS \\
\hline Middle insomnia & $0.56 \pm 0.88$ & $0.47 \pm 0.84$ & $0.31 \pm 0.63$ & NS \\
\hline Delayed insomnia & $0.44 \pm 0.88$ & $0.27 \pm 0.70$ & $0.19 \pm 0.53$ & NS \\
\hline Work interest & $2.33 \pm 1.00$ & $1.07 \pm 1.22$ & $1.31 \pm 1.33$ & $p<0.05^{2}$ \\
\hline Retarded & $1.11 \pm 1.27$ & $0.73 \pm 0.88$ & $0.97 \pm 0.99$ & NS \\
\hline Agitation & $0.22 \pm 0.44$ & $0.27 \pm 0.46$ & $0.25 \pm 0.55$ & NS \\
\hline Psychic anxiety & $2.00 \pm 1.41$ & $1.33 \pm 0.90$ & $0.94 \pm 1.07$ & $p<0.04^{3}$ \\
\hline Somatic anxiety & $1.89 \pm 1.27$ & $1.27 \pm 1.03$ & $0.72 \pm 0.91$ & $p<0.007^{4}$ \\
\hline Gastric & $0.56 \pm 0.88$ & $0.47 \pm 0.64$ & $0.28 \pm 0.57$ & NS \\
\hline General somatic & $1.00 \pm 0.87$ & $0.47 \pm 0.64$ & $0.72 \pm 0.74$ & NS \\
\hline Genital & $0.33 \pm 0.71$ & $0.00 \pm 0.00$ & $0.83 \pm 0.37$ & NS \\
\hline Hypochondriasis & $0.56 \pm 0.73$ & $0.53 \pm 0.83$ & $0.44 \pm 0.88$ & NS \\
\hline Loss of insight & $0.56 \pm 0.73$ & $1.07 \pm 0.80$ & $0.81 \pm 0.79$ & NS \\
\hline Weight loss & $1.00 \pm 1.00$ & $0.67 \pm 0.90$ & $0.25 \pm 0.60$ & $p<0.02^{5}$ \\
\hline Total & $18.7 \pm 10.5$ & $12.1 \pm 6.8$ & $11.8 \pm 6.6$ & $p<0.03^{6}$ \\
\hline
\end{tabular}

Abbreviations: $A N O V A=$ analysis of variance. $\mathrm{PDP}=$ panic disorder, probable; $\mathrm{PDD}=$ panic disorder, definite.

1. ANOVA, $F=5.33, d f=2, \rho<0.007$. Pairwise strata: PDP vs. none, NS; PDD vs. PDP, $F=10.55, p<0.002$; PDD vs. none, $F=6.42, p<0.01$

2. ANOVA, $F=3.09, d f=2, p<0.05$. Pairwise strata: PDP vs. none, NS; PDD vs. PDP, $F=5.68, p<0.02$; PDD vs. none, $F=4.79, \rho<0.03$.

3. ANOVA, $F=3.55$, $d f=2, p<0.3$. Pairwise strata: PDP vs. none, NS; PDD vs. PDP, NS; PDD vs. none, $F=6.80, p<0.01$.

4. ANOVA, $F=5.44, d f=2, p<0.007$. Painwise strata: PDP vs. none, NS; PDP vs. PDD, NS; PDD vs. none, $F=9.79, \rho<0.003$.

5. ANOVA, $F=4.31$, $d f=2, p<0.02$. Pairwise strata: PDP vs. none, NS; PDP vs. PDD, NS; PDD vs none, $F=7.20, p<0.009$.

6. ANOVA, $F=3.61 . d f=2, \rho<0.03$. Pairwise strata: PDP vs. none, NS: PDP vs. PDD, $F=4.76, p<0.03 ;$ PDD vs. none, $F=6.96, p<0.01$.

depressive illness in prepubertal children and adolescents but did not describe the presence of panic attacks in their sample.

Table 2 demonstrates the complexity of the relationship of panic attacks with previous and concurrent forms of psychiatric illness. Separation-anxiety disorder is the most common previously assigned diagnosis. Four of the patients with panic disorder met criteria for the diagnosis of this disturbance as children. Data on children from either the probable or no panic disorder groups were not available for comparison. Nevertheless, the presence of separation-anxiety among this group raises the question of whether some children were misdiagnosed as having separation-anxiety disorders when they in fact were having panic attacks. Further, a question is raised as to whether separation-anxiety disorder could be a precursor to the development of panic attacks in adolescents and adults. This raises a methodological 
issue. The KIDDIE-SADS (Chambers et al., 1985) is not designed to identify panic attacks or the diagnosis of panic disorder. Symptoms of panic attacks could be included with those defining separation-anxiety disorder. Clearly, a systematic study of "panic attacks" in prepubertal children applying either SADS-RDC or DSM-III criteria is needed.

The 10 patients with definite panic disorders included four subjects with MDD endogenous subtype, three with $\mathrm{MDD} /$ nonendogenous, two with $\mathrm{mDD}$, and one without a depressive disorder. Definite panic disorder was associated with a significantly elevated HRSD total. Psychic and somatic anxiety, guilt, work and interest, and weight loss subscale scores accounted for this elevation (see Table 4). This compares with the findings in adult samples (Van Valkenberg et al., 1984), yet there are differences between the adolescent and adult populations. In this study, the distribution of panic disorder among the four affectively ill subgroups did not differ significantly. The small sample size and a concomitant increase in the probability of a type II error could have produced this result. Nevertheless, it is noteworthy that those subjects with definite panic disorder had higher scores on the HRSD subscales of guilt, decreased work and interest, and weight loss. This has not been reported in adults with MDD and panic disorder.

With the exception of depressive disorders, BPD was the most frequent secondary diagnosis in the sample with definite panic disorder. Despite the literature describing an association between BPD and affective illness, few reports have addressed the possibility of an association between panic disorder and BPD (Akiskal, 1981; Stone, 1981; Pope et al., 1983; Grunhaus et al., 1985). These studies suggest that (1) patients with both forms of psychopathology have relatively poor response to somatic treatments, (2) both groups have higher incidences of anxiety and affective disorders in first degree relatives, (3) BPD may mark a state rather than a trait-dependent phenomenon, and (4) monoamine oxidase inhibitors might have therapeutic advantages over tricyclic antidepressants for both groups. These reports also indicate that a combination of panic attacks and MDD may mark a subgroup of patients with global disturbances previously with the label of BPD.

This report supports the idea that panic disorder is diagnosable in adolescence. It also suggests that panic and depressive disorders can be associated in adolescence as in adulthood. Because this report is based on the evaluation of inpatients with severe psychopathology, however, our findings should not be generalized to other settings indiscriminately.

Acknowledgments. The authors thank Annunciata Porterfield, Elizaheth Remkema, Karan Madsen, and Paulette Lockwood for their assistance in the preparation of this manuscript.

\section{References}

Akiskal, H.S. Subaffective disorders: Dysthymic, cyclothymic and bipolar II disorders in the "borderline" realm. Psychiatric Clinics of North America, 4, 25 (1981).

Alessi, N., McManus, M., Brickman, A., and Grapentine, W.L. The characterization of affective disorders in serious juvenile offenders. Journal of Affective Disorders, 1, 9 (1984).

Alessi, N., and Robbins, D.L. Symptoms and subtypes of depression among adolescents distinguished by the dexamethasone suppression test: A preliminary report. Psychiatry Research, 11, 177 (1984). 
American Psychiatric Association. DSM-III: Diagnostic and Statistical Manual of Mental Disorders. 3rd ed. APA, Washington, DC (1980).

Bishop, J.M., Feinberg, S.E., and Holland, P.W. Discrete Multivariate Analysis: Theory and Practice. MIT Press, Cambridge, MA, p. 395 (1975).

Bowen, R.C., and Kohout, J. The relationship betwen agoraphobia and primary affective disorders. Canadian Journal of Psychiatrv, 24, 317 (1979).

Breier, A., Charney, D.S., and Heninger, G.R. Major depression in patients with agoraphobia and panic disorder. Archives of General Psychiatry. 41, 1129 (1984).

Breier, A., Charney, D.S., and Heninger, G.R. The diagnostic validity of anxiety disorders and their relationship to depressive illness. American Journal of Psychiatry, 192, 787 (1985).

Chambers, W.J., Puig-Antich, J., Hirsch, M., Paez, P., Ambrosini, P., Tabrizi, M., and Davies, M. The assessment of affective disorders in children and adolescents by sernistructured interview: Test-retest reliability of the Schedule for Affective Disorders and Schizophrenia for school-age children, present episode version. Archives of General Psychiatry. 42, 696 (1985).

Dealy, R.S., Ishiki, D.M., Avery, D.H., Wilson, L.G., and Dunner, D.I. Secondary depression in anxiety disorders. Comprehensive Psychiatry, 22, 612 (1981).

Fawcett, J.K., and Kravitz, H.M. Anxiety syndromes and their relationship to depressive illness. Journal of Clinical Psychiatry, 44, 8 (1983).

Grunhaus, L., King, D., Greden, J.F., and Flagel, P. Depression and panic in patients with borderline personality disorder. Biological Psychiatry, 20, 688 (1985).

Gurney, C., Roth, M., Garside, R.F., and Kerr, T.A. Studies in the classification of affective disorders: The relationship between anxiety states and depressive illness. British Journal of Psychiatry. 121, 162 (1972).

Hamilton, M. A rating scale for depression. Journal of Neurology, Neurosurgeri, and Psychiatry, 23, 56 (1960).

Hershberg, S.G., Carlson, G.A., Cantrell, D.P., and Strober, M. Anxicty and depressive disorders in psychiatrically disturbed children. Journal of Clinical Psychiatry, 43, 358 (1982).

Klein, D.F. Delineation of two drug-responsive anxiety syndromes. Psychopharmacologia, 5,397 (1964).

Kovacs, M., Feinberg, T.L., Crouse-Novak, M.A., Paulauskas, S.L., and Finkelstein, R. Depressive disorders in childhood. Archives of General Psychiatry, 41, 229 (1984).

Leckman, J.F., Weissman, M.M., Merikangas, K.R., Pauls, D.L., and Prusoff, B.A. Panic disorder and major depression: Increased risk of depression, alcoholism, panic, and phobic disorders in families of depressed probands with panic disorder. Archives of General Psychiatry, 40, 1055 (1983).

Munjack, D., and Moss, H.B. Affective disorder and alcoholism in families of agoraphohics. Archives of General Psychiatry, 38, 869 (1981)

Pope, H.G., Jones, J.M., Hudson, J.I., Cohen, B.M., and Gunderson, J.G. The validity of DSM-III borderline personality disorder. Archives of Genera! Psychiatry, 40, 23 (1983).

Robbins, D.R., Alessi, N.E., Colfer, M.V.. and Yanchyshyn, G.W. Use of the Hamilton Rating Scale for Depression and the Carroll Self-Rating Scale in adolescents. Psvchiatry Research, 14, 123 (1985).

Robbins, D.R., Alessi, N.E., Cook, S., Poznanski, E., and Yanchyshyn, G.W. The use of the Research Diagnostic Criteria (RDC) for depression in adolescent psychiatric inpatients. American Academy of Child Psychiatry, 21, 251 (1982). 
Roth, M., Mountjoy, C.Q., and Caetano, D. Further investigations into the relationship between depressive disorders and anxiety states. Pharmacopsychiatrica, 15, 135 (1982).

Schapinz, K., Roth, M., Kerr, T.A., and Gurney, C. The prognosis of affective disorders: The differentiation of anxiety states from depressive illness. British .Journal of $P_{\text {sychiatry, } 121,}$ 175 (1972).

Spitzer, R.L., and Endicott, J. The Schedule for Affective Disorders and Schizophrenia. New York State Psychiatric Institute, New York (1978).

Spitzer, R.L., Endicott, J., and Robins, E. Research Diagnostic Criteria (RDC) for a Selected Group of Functional Disorders. 3rd ed. New York State Psychiatric Institute, New York (1977).

Stone, M.H. Borderline conditions: On consideration of subtypes and an overview. Directions for research. Psychiatric Clinics of North America, 4, 3 (1981).

Strober, M., Green, J., and Carlson, G. Phenomenology and subtypes of major depressive disorder in adolescence. Journal of Affective Disorders, 3, 281 (1981a).

Strober, M., Green, J., and Carlson, G. The reliability of psychiatric diagnosis in hospitalized adolescents. Archives of General Psychiatry, 38, 141 (1981 h).

Van Valkenberg, C.H., Akiskal, H.S., Puzantian, V., and Rosenthal, T. Anxiety depressions. Journal of Affective Disorders, 6, 67 (1984). 